\title{
Business Process Reengineering at ICT Operations, In Managing Smart Cities as New Customers (Non-Human)
}

\author{
Lihardo Ranjaliba Saragih $^{1 *}$, Muhammad Dachyar¹, Teuku Yuri M. Zagloel ${ }^{1}$ \\ ${ }^{1}$ Department of Industrial Engineering, Faculty of Engineering, Universitas Indonesia, Kampus UI Depok, Depok \\ 16424, Indonesia
}

\begin{abstract}
TELCO is an information communications technology (ICT) company that has a typically high cost, especially for the provisioning and maintenance of its infrastructure. The emergence of over-the-top (OTT) media services, which do not make expensive infrastructure investments, such as the WhatsApp $\AA$ and Zoom ${ }^{\circledR}$ applications that are now massively being used, has resulted in many TELCO services becoming obsolete. This phenomenon occurs because OTT is pragmatically able to substitute similar services. Reflecting on the capabilities of connectivity and coverage, TELCO needs to create a new market by paying special attention to smart cities that are constructed from massive devices with internet connections. The current TELCO operational business model is based on human customers, whereas smart cities are a multi-service digital (non-human) city council, so a new business process is required to manage smart city (non-human) customers. This research presents the transformation of business processes in the customer domain in the complex systems operations of a TELCO company. The research novelty is the business process reengineering (BPR) method combined with soft systems methodology (SSM) and enterprise knowledge development (EKD) to define, map, model, and project a new business process. The result of this research is an enterprise architecture (EA) "request to answer" model for managing new smart city customers. In the end, it is expected to increase TELCO's competitiveness.
\end{abstract}

Keywords: Business process reengineering (BPR); Enterprise architecture (EA); Smart cities; Soft system methodology (SSM); TELCO operations

\section{Introduction}

Digital transformation is becoming an important topic for companies around the world (Harmon, 2019; von Leipzig et al., 2017), including for telecommunications companies (TELCO) which is the object of this research. TELCO operates in a competitive dynamic environment (Oughton et al., 2018), characterized by high investment, especially for the provisioning and maintenance of infrastructure, as technology is always changing rapidly, and a typical company is agile, meaning flexible and responsive. The confrontational situation in the digital economy era has created the VUCA ecosystem: volatility, uncertainty, complexity, and ambiguity (Kale, 2019). The confrontation occurs between TELCO and over-the-top (OTT), as OTT pragmatically offers TELCO services without investing in expensive infrastructure procurement at all. This has resulted in disruption to TELCO in terms of primary products (voice and text), resulting in decreased revenues and reduce

${ }^{*}$ Corresponding author's email: ranjaliba@gmail.com, Tel.: +62-2178888805; Fax: +62-2178885656 doi: 10.14716/ijtech.v12i2.4418 
market dominance, which is called company turbulence.

The digital phenomenon is transforming cities into a large market, wherein every resident, student, tourist, and businessman becomes a potential target through communication channels such as smartphones, tablets, and others (N'Goala et al., 2019). This transformation brings a massive non-human market (Suryanegara, 2016). The smart city concept is part of the application of the internet of things (IoT), which requires connection services and internet coverage that are carried by a TELCO. The massive multiindustry growth of IoT is a big opportunity for a TELCO to generate profits in a mature market (ITU, 2018) by applying a "market development" plan, according to Ansoff matrix strategy (Drucker, 2007; Ansoff et al., 2019; Hague, 2019) by paying special attention to the smart city as a new (non-human) customer. However, TELCO currently only has a business process for human customers. safety.

Business process reengineering (BPR) was first introduced (Hammer and Champy, 1993) more than two decades ago as a new method for the fundamental redesign and rethinking of all existing processes. The BPR method is used to produce better overall process performance in quality, cost, service, and processing time. BPR research has developed mature knowledge of how to model, analyze, automate, and streamline processes, known as exploitative BPR (Ohlsson and Han, 2017). This approach has supported fixing the problems identified in the process, but this approach is only useful for the short term. Therefore, BPR researchers and practitioners encourage an exploratory approach, which is known as "explorative BPR." Rosemann (2014) emphasized that BPR research with an exploratory approach is a serious future opportunity and challenge. Organizations that have successfully used BPR methods to generate competitive advantage not only overhaul existing processes, but simultaneously introduce unique concepts and objectives based on strategic innovation (Dachyar et al., 2015).

In addition to the knowledge base of BPR explorative research, the presence of systems thinking also influences process design. The systems and management science are heavily influenced by the goal-seeking paradigm, which is called "hard systems thinking." Researchers have criticized this paradigm because of its limitations for management use. Checkland argues that the "hard" paradigm is incapable of dealing with organizational complexity, with a plurality of different beliefs and values, and cannot help in the presence of political factors and power maneuvers in companies (Checkland, 2007). Another limitation of hard systems thinking is unsatisfactory performance in dealing with multiple perceptions of reality (Jackson, 2003). Soft systems methodology (SSM) is present in the context of the problem for focusing on systems models that express different viewpoints so that alternative perspectives can be systematically explored, compared, and contrasted. SSM is a theory that has brought about company organization as a social system (Checkland, 1999), commitment to network organization, and rationality in decision making (Ohlsson and Han, 2017). SSM involves enterprise knowledge development (EKD) in designing conceptual models that apply guidelines for participatory ways of working, and languages for expressing enterprise modeling based on Stirna and Persson (2018). BPR's best practice in redesigning processes includes task elimination, task composition, integral technology, empowering, order assignment, resequencing, specialist generator, integration, parallelism, and numerical involvement (Mansar and Reijers, 2007; Kumar and Bhatia, 2012).

The research problems formulated include the complexity of the TELCO company system and organization, business process information gaps, and the uncertainty of business models and IoT service standards. Each company has its own uniqueness and exclusiveness (Tatiana and Mikhail, 2020). TELCO and smart city business processes have 
different characteristics and contexts in the organization. Business processes are understood as the formal operation and process behavior that can be understood through the construct of adaptive interpretation of SSM. The activities and knowledge of humans are very important in redesigning the process, therefore the enhanced telecom operations map (eTOM) is needed to obtain the holistic TELCO business process.

The international telecommunication union (ITU) provides recommendations for TELCO management and operations based on eTOM (ITU, 2007). eTOM discusses the customer-centric domain that comprises activities from an end-to-end perspective, starting and ending with the customer (TMForum, 2018), such as "request to answer" (R2A). Transforming the customer business process is redesigning new business processes for smart city customers in TELCO. The context of TELCO is smart city connectivity so that the stakeholder can collect information on each IoT device according to their business needs, by providing a connection between the real and virtual worlds (N'Goala, 2019).

Based on the ontology, the reality of the nature of a telecommunications company is a complex enterprise system; SSM has a function to solve problems in a situation/problem situation, and guide interventions to reduce them by expressing model systems so that researchers can have alternative perspectives to explore, compare, and contrast the problem systemically. The EKD method plays a role in designing the SSM conceptual model based on participatory variables and enterprise architecture (EA) language notation to express strategic modelling for business process transformation in the company. Meanwhile, the BPR method is a rule in the redesign process, including the elimination of tasks, the composition of tasks, integral technology, empowerment, and others.

The formulation of questions in this study includes: (1) what business activities will be changed through this research; (2) how to identify current business processes (as is) and how they can move to future business processes (to be); and (3) how to describe the conceptual model. The purpose of this study is to obtain a business process transformation model, a TELCO enterprise architecture model that presents new organizational competitiveness in TELCO operations in managing smart city (non-human) customers to overcome the company's turbulence. The novelty of this study is the combination method of BPR, EKD, and SSM that focus on projecting the new model of customer-centric business processes at TELCO operations. Besides, a smart city is redefining business processes in TELCO companies as a new type of non-human customer that doesn't yet exist. The research presents future opportunities in terms of the scope and depth of business process studies in companies, including the range of cases

\section{Methods}

This research uses a qualitative approach in the analysis and design of business process strategy models in telecommunications companies. A qualitative approach is used because business process analysis is based on combination methods that involve human activities in complex process flows, in humanist corporate organizations. This reality becomes impossible to understand, except qualitatively.

\subsection{Research Methodology}

The research design collaborates with BPR and SSM for redesigning a complex set of processes in the company as depicted in Figure 1. The knowledge gained from the exploratory approach used for redesigning and rethinking, as based on BPR best practice, is the starting point for analyzing, modeling, automating, and streamlining the processes in systems. BPR is run through SSM stages, in order to produce a different viewpoint as an 
alternative perspective in the organizational context, as a social system in the TELCO operations business process.

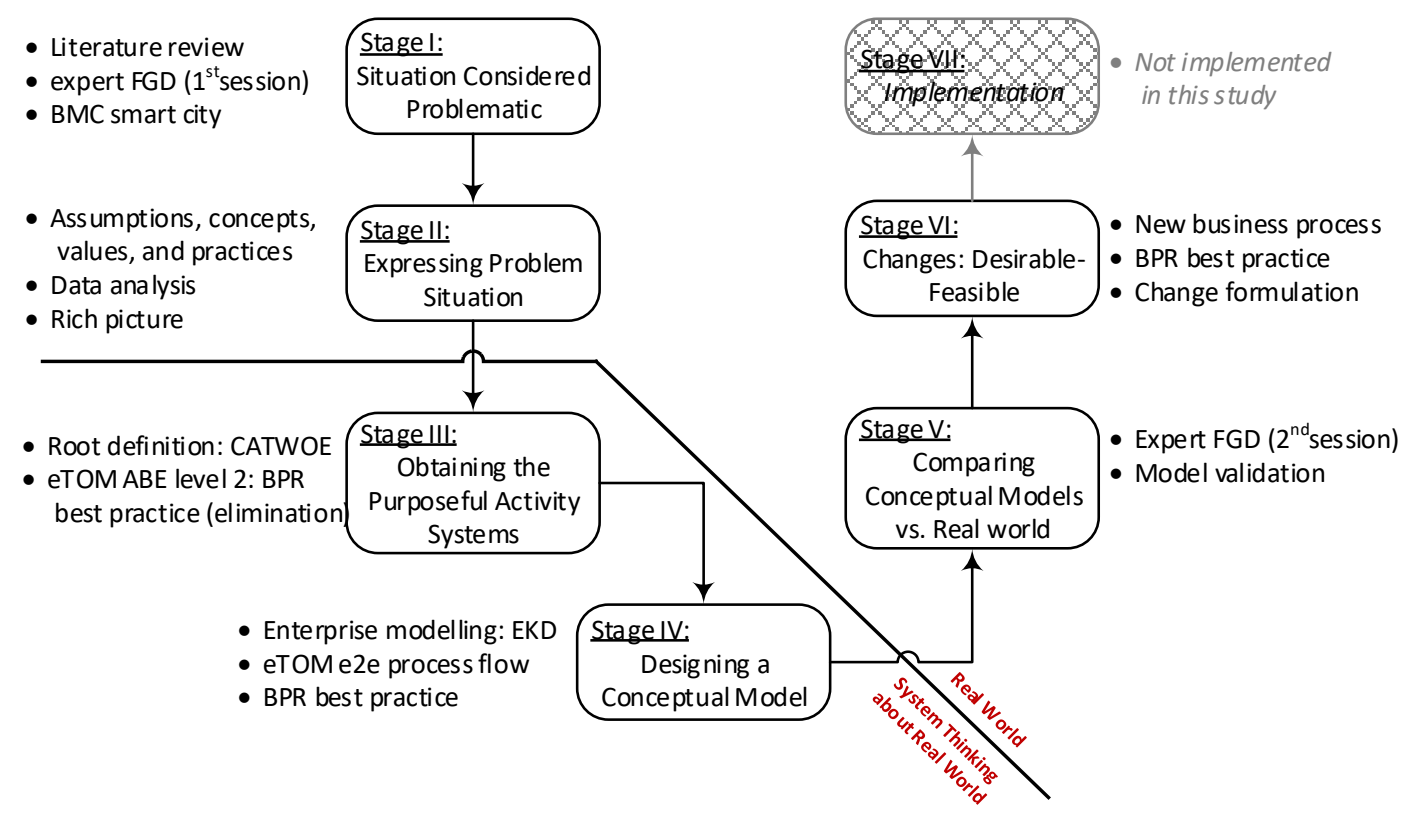

Figure 1 Research methodology - a combination of BPR and SSM methods

In the business process transformation phase, the company undertakes the critical examination, rethinking, and then redesigning of current business processes, practices, and rules. The model is developed in several steps following SSM stages. The first step of SSM is a literature review regarding what concepts can be utilized, and their scientific combination through their ontology. After that, the first session of focus group discussion (FGD) was conducted with TELCO experts to find problems and research opportunities, including to obtain problem situations from secondary data sources from the smart city business model canvas (BMC). The second step of SSM is to build assumptions, concepts, values, and practices related to customer-centric business processes, analyze the data, and put the data in a free sketch design to express the problem, which is called a "rich picture".

The third step of SSM defines customers, actors, transformations, world views, owners, environmental constraints (CATWOE), and the aggregate business entity (ABE) of the eTOM business process to determine which business processes can be used in research based on BPR best practices. The fourth step is to design a conceptual model with EKD guidelines to produce an enterprise architecture (EA). The fifth step of SSM is to conduct a second FGD with TELCO experts to validate the conceptual model by way of business process confirmation and model redesign. Then, in the sixth step, SSM is the redesign of business processes in the EA model according to BPR best practices and the results of comparisons that have been obtained. The seventh step of SSM regarding implementing business processes is something that is beyond control and cannot be done, so it is outside the context of the research.

\subsection{Primary Data Sources and Expert Characteristics}

Primary data were collected by conducting FGD with TELCO experts based on research instruments. The FGD scheme was carried out through a form of group interview led by a moderator/facilitator; the data generated came from qualitative interviews and group interactions, which discussed topics given by the researcher. FGD treatment produced a collective view rather than an individual view (Cohen et al., 2017). 
Credible experts with their respective competencies are members of the FGD. The researcher determines the criteria of an expert who is eligible as a reference source, coming from a national cellular telecommunications association, and the two largest telecommunications operator companies. Experts are senior employees with mature experience in the TELCO industry and have positions in strategic enterprise units. The data collection stage consisted of two sessions. The first FGD session was conducted at each office location of the TELCO T, TELCO X, and TELCO company associations. Then the second FGD session was held at TELCO company $\mathrm{T}$, as a company whose business process will be changed.

\subsection{Secondary Data Sources}

Secondary data sources use the smart city smartSantander business model, through the BMC model in research conducted by Díaz-díaz et al. (2017), which addresses eight use cases: waste management, water supply, tourism promotion, smart traffic management, smart street lighting, city incident management, park irrigation, and citizen engagement management. BMC is considered to represent the information needed for the smart city business process, according to Welfare (2019); smartSantander with city/urban scale represents the most attractive and complete option, and is built with the aim of creating a unique experimental research and testing facility worldwide.

Another secondary dataset is the business framework eTOM version 20.0 (TMForum, 2020), which covers 2,179 business processes in context and uses detailed descriptions for TELCO operations and their decompositions. Business processes are covered in 1,906 pages of the GB921 documentation.

\subsection{Research Instrument}

The questionnaire and interview are explored in the questionnaire checklist forms (Table 1), representing the initial best practice that functioned as the underlying business process of the similar understanding model between researcher and expert in the FGD sessions. Additional information obtained during the FGD process, due to certain materials, naturally leads to spontaneous questions/answers between moderators and experts.

Table 1 The questionnaire checklist, and FGD material ${ }^{*}$

\begin{tabular}{ll}
\hline \multicolumn{1}{c}{ Information type } & \multicolumn{1}{c}{ Detail } \\
\hline Expert demography & Name, date, time, place, specialty, how long in current practice \\
& \& employment, position or level, age, gender \\
Mobile communications technology & GSM, CDMA_2000, LTE, WCDMA, NR, other \\
Customer (self-care) channels & Web/apps (e-care), SMS, IVR, USSD, twitter/FB/IG, other \\
Telecommunications services & Voice, SMS, GPRS, MMS, VMS, MCN, M2M, others \\
Contact customers and vice versa & Contact customer: SMS, email, letter, contact center, other \\
& Contact TELCO: contact center, e-care, IVR, USSD, SMS, etc. \\
Subscriber's life cycle & Idle, active, suspended, disabled, de-activated / pooled \\
Customer care - basic function list & 360-degree customer view, customer management, service \\
& changing, service management, batch operation \\
${ }^{*}$ Business process of customer-centric & Request-to-answer process flow based on eTOM \\
service & \\
\hline
\end{tabular}

\section{Results and Discussion}

\subsection{BPR-SSM Stage 1: Situation Problem}

Business process "request to answer" (R2A) at TELCO operations starts from the service question events requested by a customer candidate (see Table 2). The high-level company support is covered through interface or media that builds communication very 
well between the customer candidate and the sales team. The question is then analyzed in order to be answered, based on the existing product along with the features, specifications, and price list. The question can also be as a request, which has the possibility for a TELCO to make some modifications to the existing product. The customized product needs to analyze the feasibility of new development with the specific effort, cost, and development period. More technical analysis activities may also be forwarded to the technology domain based on customization or new development. The final output is the business contract proposal document for both customers and TELCO.

Table 2 Situation problem in business process "request to answer"

\begin{tabular}{llll}
\hline \multicolumn{2}{c}{ Smart cities (customer candidate) } & & TELCO operations \\
\hline \multicolumn{1}{c}{ BMC nine blocks } & Request/inquiry & Response/answer & \multicolumn{1}{c}{ Problems (what, how) } \\
\hline $\begin{array}{l}\text { Key partnership, key } \\
\text { resources, key }\end{array}$ & Connectivity, & Request handling & Input: customer interface for smart \\
technology & product, offer & cities? and inquiry identification? \\
propositions, & readiness, & preparation, & Process: customer contact \\
customer & coverage, product & handling, others. & management? and Sales contract \\
relationship, & catalog, etc. & & proposal development? \\
channels, customer & & & Output: Sales contract proposal \\
segment, cost, & & & result? proposal send/received? \\
revenue. & & & \\
\hline
\end{tabular}

\subsection{BPR-SSM Stage 2: Rich Picture}

This second stage provides a rich picture that helps analyze human communication channels, information, and knowledge flow within channels. Rich pictures are built using assumptions, concepts, values, and practical examples based on problem analysis in the process of "request to answer". The concept of this process consists of activities relevant to responding or managing customer requests that exist across all available communication channels (customer interface). The target of this business process is a request for specific information or a product that comes from a customer that is eligible and can be handled. The value of this process is an opportunity that can lead to the preparation of a pre-sale offer if a customer shows an interest in a particular product. Practical assumptions and examples are shown in Table 3.

Table 3 Assumptions and samples

\begin{tabular}{ll}
\hline \multicolumn{1}{c}{ Assumptions } & \multicolumn{1}{c}{ Samples } \\
\hline - Bid preparation may or may not lead to prior & $\bullet$ Customers call/come directly / use certain \\
company resource reservations/reservations & media to ask for product and price info \\
- Company resources can be reserved or secured & $\bullet$ Customers come to TELCO offices because they \\
$\begin{array}{l}\text { for specific products or customers, depending on } \\
\text { the telecommunications operator company }\end{array}$ & $\begin{array}{l}\text { are interested in upgrading their services } \\
\text { based on the new 4G / 5G SIM cards with a }\end{array}$ \\
policies and procedures & special package service \\
- If the offer is accepted by the customer, this & $\bullet$ Customers browse websites to explore offers \\
process will then trigger another business & $\bullet$ Customers send e-mails to get product catalogs \\
process: "Order to payment" & \\
\hline
\end{tabular}

Rich Picture is a technique of capturing problem interactions in picture descriptions of all the important elements of the problem in an organization or business activity, thereby facilitating a more holistic understanding and analysis. There are no rules about what can or cannot be captured in a rich picture (Cadle et al., 2014), including what symbols to use, so it's a very free format technique. Please see Figure 2. 


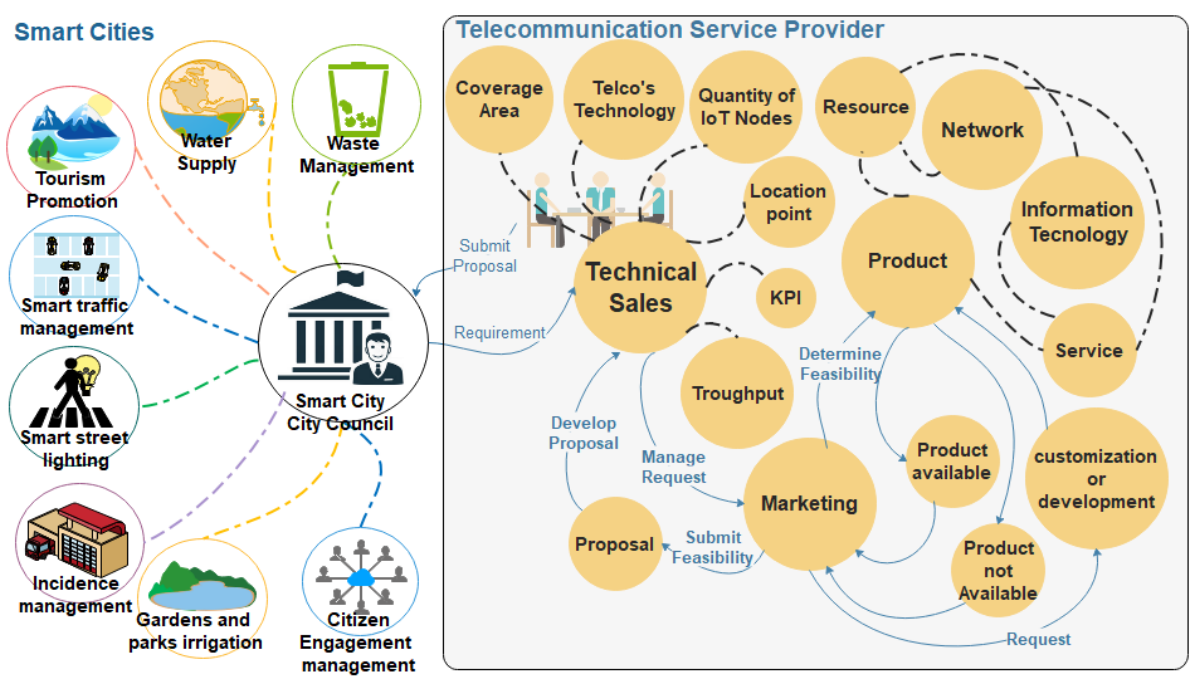

Figure 2 Rich picture for business process "request to answer"

\subsection{BPR-SSM Stage 3: CATWOE}

The third stage builds the root definition of the "request to answer" business process in TELCO operations using the CATWOE tool as shown in Table 4. Root definition explores the organization as a social system consisting of various actors and conditions that define the systemic work of business processes. Root definitions are viewpoints as an alternative perspective that enables the presence of change, and certain constraints that will affect the rationality in decision making of the architect that makes this business process.

Table 4 Root definition with CATWOE

\begin{tabular}{|c|c|}
\hline CATWOE & "Request to Answer" \\
\hline C, Customers & $\begin{array}{l}\text { City council as a smart city project manager, concession representative from waste } \\
\text { management, water supply, tourism promotion, smart traffic management, smart } \\
\text { street lighting representative, etc. }\end{array}$ \\
\hline A, Actors & Customer service center (GPR囚) staff, customer care online (CRN $($ ) agent \\
\hline $\begin{array}{l}\text { T, Transformation } \\
\text { Process } \\
\text { (Proposed) }\end{array}$ & $\begin{array}{l}\text { Provide a communication channel for customer requests independently: } \\
\text { - Provides a customer service center (GPR囚) interface for smart cities } \\
\text { - Provides an online customer service interface (CRN囚) (self-service) } \\
\text { - Smart city representatives can find information about the product catalog } \\
\text { - Telecom operators are able to manage smart city contacts } \\
\text { - Register a new customer type: Smart city } \\
\text { - Each smart city has a unique customer ID to differentiate customers } \\
\text { - The customer's unique ID can refer to the new MSISDN prefix number } \\
\text { - Availability of a team to conduct a Feasibility Study for a smart city } \\
\text { - In-house team of experts supporting the demand for smart city specifications } \\
\text { - Assessment of internal revenue estimates, including value for customers } \\
\text { - Offer contract proposal with detailed investment BoQs, KPIs \& payment terms } \\
\text { - Respond to requests for technical documentation of connectivity } \\
\text { - Provides a product catalog, SLA, and QoS devices } \\
\text { - Infrastructure capabilities related to guaranteed SLAs }\end{array}$ \\
\hline W, World View & Manage customer industries, with available resources and constraints \\
\hline O, System Owners & Smart city council. Directorate of sales of TELCO operator companies \\
\hline $\begin{array}{l}\text { E, Environment } \\
\text { (constraints) }\end{array}$ & $\begin{array}{l}\text { Time, number of customers, over commits, seamless service, standardization, } \\
\text { complexity, customer satisfaction, presence of contact centers, and channels }\end{array}$ \\
\hline
\end{tabular}

\subsection{BPR-SSM Stage 4: Conceptual Design}

Stage 4 builds the "request to answer" business process conceptual model by implementing EKD as an approach to corporate modeling that supports creativity and 
quality in the design of enterprise architecture (EA) and business development. EKD modeling involves semantically rich notation involving all sub-elements (Table 5) and their respective attributes to be modeled according to the flow diagram (Figure 3), in the context of "request to answer" business process modeling at TELCO operations. In generating a model, apart from getting the overall attributes and context of the business process, modeling also requires a higher level of formality, and/or stakeholders have more experience with modeling, especially for architects who have experience in the practice area of TELCO operations.

Table 5 An overview of the EKD method sub-model

\begin{tabular}{|c|c|c|c|c|c|c|}
\hline EKD & Goals model & Business rules model & $\begin{array}{c}\text { Actors \& } \\
\text { resource } \\
\text { model }\end{array}$ & $\begin{array}{c}\text { Business } \\
\text { process model }\end{array}$ & $\begin{array}{c}\text { Technical } \\
\text { components \& } \\
\text { requirement } \\
\end{array}$ & $\begin{array}{l}\text { Concept } \\
\text { model }\end{array}$ \\
\hline Focus & $\begin{array}{l}\text { TELCO new } \\
\text { operations vision } \\
\text { and strategy }\end{array}$ & Modeling policy and rules & $\begin{array}{l}\text { Enterprise } \\
\text { organization } \\
\text { structure }\end{array}$ & $\begin{array}{l}\text { TELCO } \\
\text { operations }\end{array}$ & $\begin{array}{l}\text { EA systems } \\
\text { needs }\end{array}$ & $\begin{array}{l}\text { Causality } \\
\text { context of a } \\
\mathrm{PQR} \\
\text { interaction }\end{array}$ \\
\hline$\overline{\text { Issues }}$ & $\begin{array}{l}\text { What is the } \\
\text { organization } \\
\text { trying to achieve } \\
\text { or avoid \& why? }\end{array}$ & $\begin{array}{l}\text { What is the appropriate BPR } \\
\text { best practice? }\end{array}$ & $\begin{array}{l}\text { Who/what } \\
\text { is } \\
\text { responsible } \\
\text { for goals \& } \\
\text { process? }\end{array}$ & $\begin{array}{l}\text { What is the } \\
\text { business (sub) } \\
\text { process? How do } \\
\text { they process } \\
\text { information? }\end{array}$ & $\begin{array}{l}\text { What are the } \\
\text { EA business } \\
\text { requirements? } \\
\text { How they } \\
\text { interact? }\end{array}$ & $\begin{array}{l}\text { Doing P? } \\
\text { with Q? in } \\
\text { order to } \\
\text { make R? }\end{array}$ \\
\hline $\begin{array}{l}\overline{\text { Compc }} \\
\text { nents }\end{array}$ & $\begin{array}{l}\text { CATWOE: } \\
\text { Customers, actors } \\
\text { transformations, } \\
\text { world view, } \\
\text { owner, } \\
\text { environment } \\
\text { constraints }\end{array}$ & $\begin{array}{l}\text { BPR best practice: task } \\
\text { elimination/composition, } \\
\text { integral technology, order } \\
\text { assignment, empower, } \\
\text { resequencing, specialist } \\
\text { generator, integration, } \\
\text { parallelism, numerical } \\
\text { involve }\end{array}$ & $\begin{array}{l}\text { Actor, role, } \\
\text { interactions, } \\
\text { organization } \\
\text { al } \\
\text { directorate }\end{array}$ & $\begin{array}{l}\text { eTOM aggregate } \\
\text { business entity } \\
\text { (ABE) through } \\
\text { decom-positions } \\
\text { level } 2,3 \text {, and } 4\end{array}$ & $\begin{array}{l}\text { EA elements of } \\
\text { business, } \\
\text { application, } \\
\text { technology, } \\
\text { grouping }\end{array}$ & $\begin{array}{l}\text { Flow, } \\
\text { triggering, } \\
\text { assignment, } \\
\text { serving, } \\
\text { realization }\end{array}$ \\
\hline
\end{tabular}

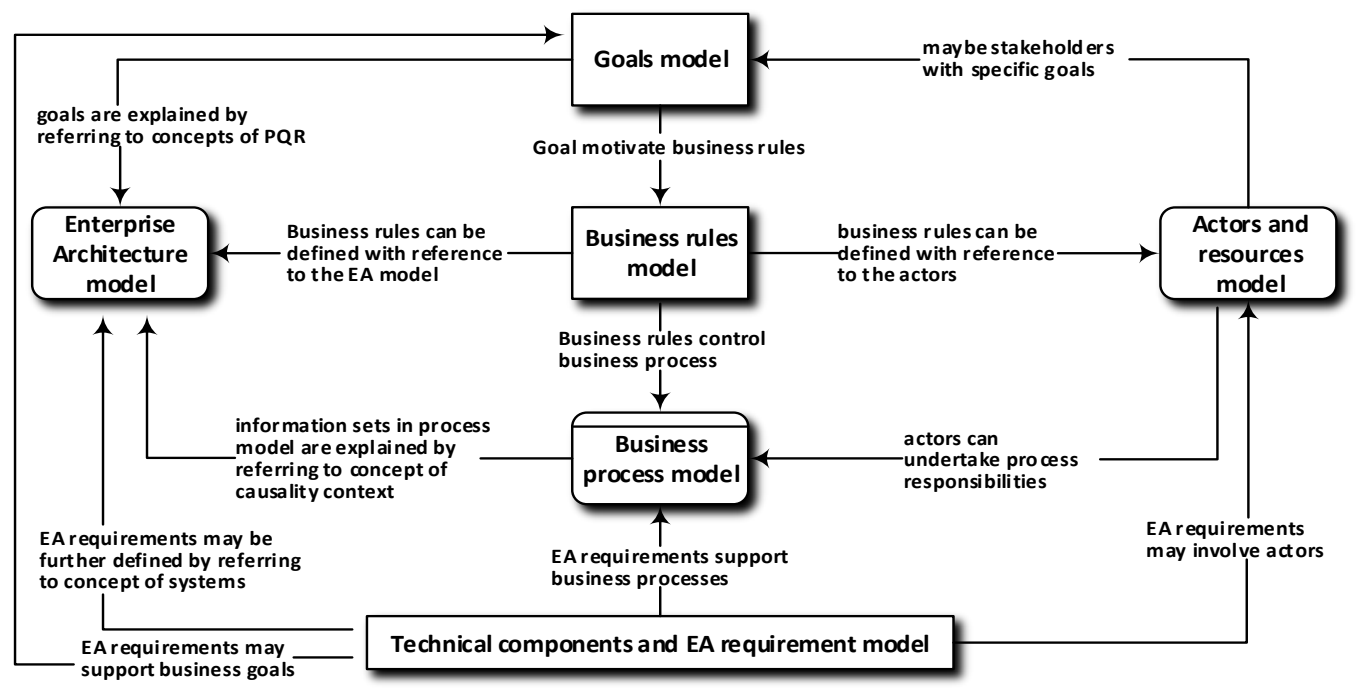

Figure 3 EKD enterprise modeling (Stirna and Persson, 2018) for BPR-SSM conceptual model development

\subsubsection{Defines a segment goals model: R2A}

The goals segment is the goal to be achieved from each detailed mapping carried out in the EKD method. In the concept of SSM, CATWOE tools generate goals as information on what business process transformation one wants to achieve. 


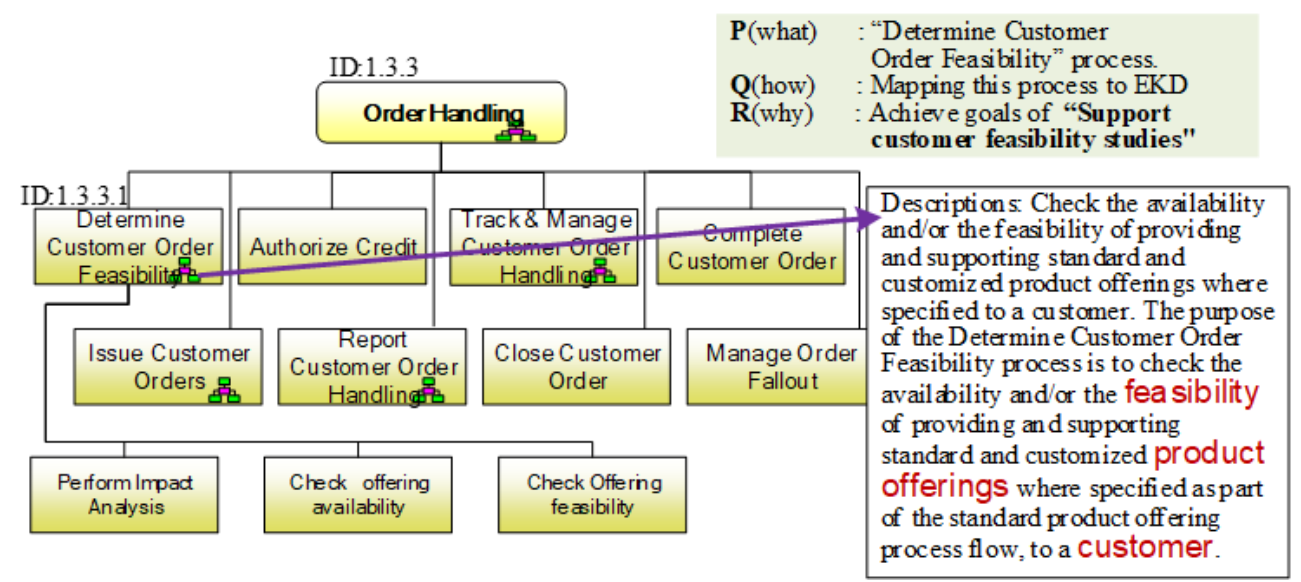

Figure 4 One of the business process model fragments for the R2A business process

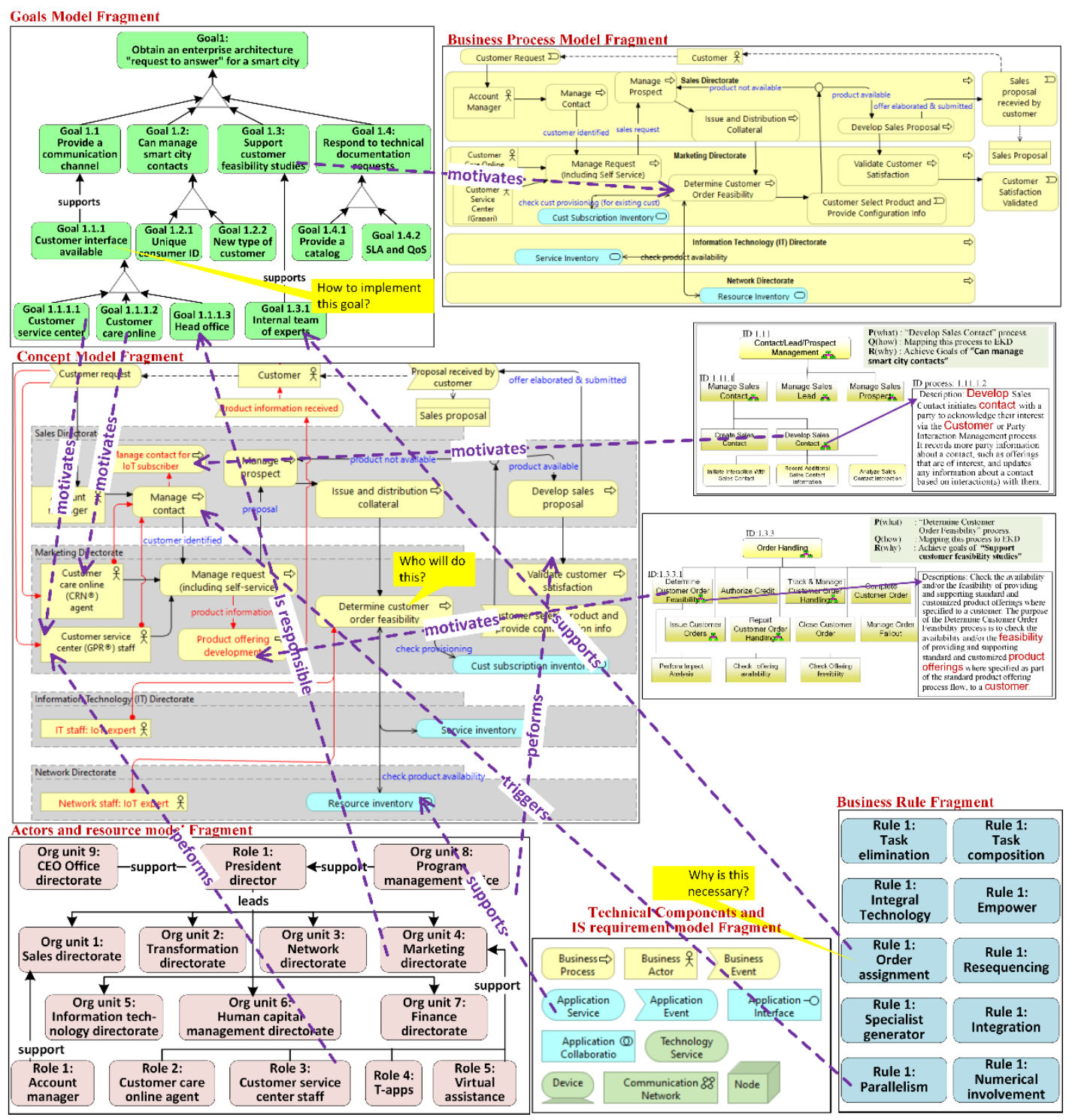

Figure 5 SSM 4 inter-model link for business process R2A

\subsubsection{Defines a segment of the business process model: R2A}

Changed business activities are derived from the business process model segment. The segment business process model is an aggregation of business entities, which is built based 
on the description of eTOM activities, that have the intention of achieving goals. The business entity is obtained through an in-depth definition of eTOM's semantic description with PQR.

\subsubsection{Strategy model for future business processes (to be): R2A}

The identification of current business processes (as is) to achieve future business processes (to be) is carried out while undergoing the EKD method. Enterprise modeling using the EKD method generates a future model from the results of the inter-model link mapping of the six model fragments. The results of the SSM conceptual model are obtained through this mapping mechanism.

\subsection{BPR-SSM Stage 5 and 6: EA as a New Business Process}

Stage 5 makes a comparison of the resulting conceptual model with the real business process model in the company (as is), while in stage 6 the business process model is changed to become a new EA model that is systemically desirable and willing to apply to the company organization, because it is culturally ready to apply to TELCO operations.

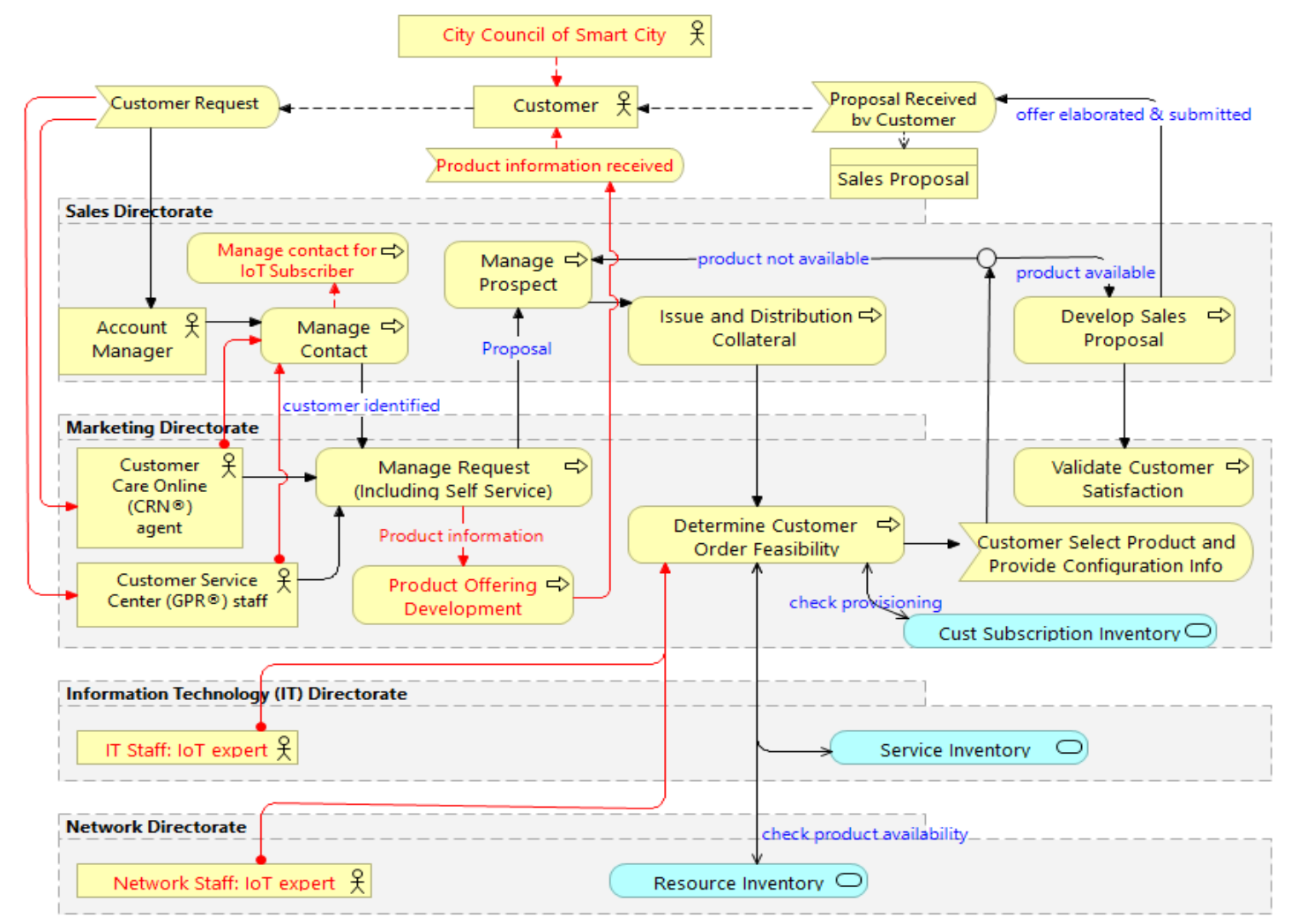

Figure 6 Enterprise architecture model of TELCO operations (before and after transformation)

The new EA as a result of business process transformation in TELCO operations in managing new smart city customers is shown in Figure 6. The EA is displayed in ArchiMate language notation. The conceptual model description is obtained by capturing the EA elements: business (yellow highlight), application (blue highlight), technology (green highlight), the relationship between elements (arrows shape). The red (highlight) elements are the gap towards collaboration with the smart city as a future strategy. Grouping (shape) is the location of the directorate for conducting business activities.

Based on Buckl et al. (2009), the analysis of a holistic EA model uses a five-dimensional classification scheme: body of analysis (structure), time reference, analysis technique (expert-based), analysis concern (functional), and self-referentiality (multi-level). With EA's technical feasibility for new non-human (smart city) customers, the company will 
require additional human resources, additional job descriptions, smart city product catalogs and product proposals, and changes to the customer relationship management (CRM) application, specifically, the $\mathrm{CRN} 囚$ and GPR $\AA$ interfaces. Meanwhile, from an economic perspective, further budget analysis is required through capital expenditure (CAPEX) and operational expenditure (OPEX) (Manzur et al., 2015), depending on business elements, applications, and changing/additional technology.

\section{Conclusions}

The final result of this research is the EA model which shows the transformation of the business process. This transformation model presents a new organizational capability for TELCO operations in managing new smart city (non-human) customers. The future "request to answer" business process will create three changes: manage contacts, manage requests (including self-service), and determine customer order feasibility. The future business processes also lead to the emergence of two new business processes: managing contacts for IoT subscribers, and product offering development.

Identification of current business processes (as is) in TELCO organizations is obtained through eTOM end-to-end process flow analysis and soft system methodology (SSM), while future business processes (to be) are obtained by combining BPR and SSM methods. SSM stage four (4) develops a conceptual model by implementing the EKD method. EKD involves semantically rich notation of all activity elements (processes/subprocesses of the smart city and TELCO), and the attributes of their respective notations, for then constructing the system following EKD's flowchart guidelines in the causality context of "request to answer" at TELCO operations.

The research has limitations in the depth of business process design, the context of which is too detailed, so that the decomposition of business processes at the sub-process level, which has a deeper context, can be carried out in further research. In addition, the business process analysis in this study focuses on the core business activities of TELCO operational activities, not other supporting business processes such as human resources, finance, assets, infrastructure, products, and others. This study opens research to collaboration between TELCO operations and multiple other industries, with a similar approach to managing as new customers (non-human).

\section{References}

Ansoff, H.I., Kipley, D., Lewis, A.O., Helm-Stevens, R., Ansoff, R., 2019. Implanting Strategic Management. 3rd Edition. Palgrave Macmillan

Buckl, S., Matthes, F., Schweda, C.M., 2009. Classifying Enterprise Architecture Analysis Approaches. Lecture Notes in Business Information Processing, Volume 38 LNBIP (October 2009), pp. 66-79

Cadle, J., Paul, D., Turner, P., 2014. Business Analysis Techniques: 99 Essential Tools for Success. BCS, The Chartered Institute for IT

Checkland, P., 1999. Systems Thinking, Systems Practice. USA: John Wiley \& Sons, Ltd

Checkland, P., 2007. Soft Systems Methodology: A 30-Year Retrospective. USA: John Wiley \& Sons, Ltd

Cohen, L, Manion, l., Morrison, K., 2017. Research Methods in Education. London: Taylor \& Francis

Dachyar, M., Yadrifil, Pratama, N.R., 2015. Development of Strategy Model for Organizational. International Journal of Technology, Volume 6(2), pp. 284-290

Díaz-Díaz, R., Muñoz, L., Pérez-González, D., 2017. Business Model Analysis of Public 
Services Operating in the Smart City Ecosystem: The Case of SmartSantander. Future Generation Computer Systems, Volume 76, pp. 198-214

Drucker, P.F., 2007. The Effective Executive. UK: Butterworth-Heinemann

Hague, P., 2019. The Business Models Handbook: Templates, Theory and Case Studies. London: Kogan Page

Hammer, M., Champy, J., 1993. Reengineering the Corporation: A Manifesto for Business Revolution. Business Horizons

Harmon, P., 2019. Business Process Change: A Business Process Management Guide for Managers and Process Professionals. 4th Edition. USA: Morgan Kaufmann

ITU, 2007. M.3050: Enhanced Telecom Operations Map (ETOM) Supplement 4: An ETOM Primer

ITU, 2018. Measuring the Information Society Report

Jackson, M.C., 2003. Systems Thinking, Creative Holism for Managers. John Wiley \& Sons Ltd Kale, V., 2019. Digital Transformation of Enterprise Architecture. USA: CRC Press

Kumar, D., Bhatia, A., 2012. BPR: Organization Culture, Best Practices and Future Trends. International Journal of Computer Applications, Volume 44(23), pp. 1-5

Von Leipzig, T., Gamp, M., Manz, D., Schöttle, K., Ohlhausen, P., Oosthuizen, G., Palm, D., von Leipzig, K., 2017. Initialising Customer-Orientated Digital Transformation in Enterprises. Procedia Manufacturing, Volume 8, pp. 517-24

Mansar, S.L., Reijers, H.A., 2007. Best Practices in Business Process Redesign: Use and Impact. Business Process Management Journal, Volume 13(2), pp. 193-213

Manzur, L., Ulloa, J.M., Sánchez, M., Villalobos, J., 2015. XArchiMate: Enterprise Architecture Simulation, Experimentation and Analysis. Simulation, Volume 91(3), pp. 276-301

N'Goala, G. (ed.), Pez-Pérard, V. (ed.), Prim-Allaz, I. (ed.). 2019. Augmented Customer Strategy: CRM in the Digital Age. John Wiley \& Sons

Ohlsson, J., Han, S.,. 2017. Prioritising Business Processes: Design and Evaluation of the Prioritisation and Categorisation Method (PCM). Springer International Publishing

Oughton, E., Frias, Z., Russell, T., Sicker, D., Cleevely, D.D., 2018. Technological Forecasting \& Social Change Towards 5G: Scenario-Based Assessment of the Future Supply and Demand for Mobile Telecommunications Infrastructure. Technological Forecasting \& Social Change, Volume 133, pp. 141-155

Rosemann, M., 2014. Proposals for Future BPM Research Directions. In: Asia-Pacific Conference on Business Process Management, Australia, July 3-4

Stirna, J., Persson, A., 2018. Enterprise Modeling: Facilitating the Process and the People. Switzerland: Springer International Publishing

Suryanegara, M., 2016. 5G as Disruptive Innovation: Standard and Regulatory Challenges at a Country Level. International Journal of Technology, Volume 7(4), pp. 635-642

Tatiana, B., Mikhail, K., 2020. Problems of Competitive Strategy Choice According to Industry and Regional Factors. International Journal of Technology, Volume 11(8), pp. 1478-1488

TMForum, 2018. GB921E End-to-End Business Flows. Available Online at https://www.tmforum.org/resources/standard/gb921e-end-to-end-business-flowsr17-5-0/, Accessed on June 28, 2020

TMForum, 2020. GB921DX Frameworx Standard, Business Process Framework (ETOM). TM Forum Release. Available Online at https://www.tmforum.org/downloadframeworx/, Accessed on June 28, 2020

Welfare, A., 2019. Commercializing Blockchain: Strategic Applications in the Real World. USA: John Wiley \& Sons, Ltd. 